\title{
TU/e EmonOWEN

\section{Effects of fit and bonding characteristics of femoral stems on adaptive bone remodeling}

Citation for published version (APA):

Weinans, H., Huiskes, H. W. J., \& Grootenboer, H. J. (1994). Effects of fit and bonding characteristics of femoral stems on adaptive bone remodeling. Journal of Biomechanical Engineering: Transactions of the ASME, 116(4), 393-400. https://doi.org/10.1115/1.2895789

DOI:

10.1115/1.2895789

Document status and date:

Published: 01/01/1994

\section{Document Version:}

Publisher's PDF, also known as Version of Record (includes final page, issue and volume numbers)

\section{Please check the document version of this publication:}

- A submitted manuscript is the version of the article upon submission and before peer-review. There can be important differences between the submitted version and the official published version of record. People interested in the research are advised to contact the author for the final version of the publication, or visit the $\mathrm{DOI}$ to the publisher's website.

- The final author version and the galley proof are versions of the publication after peer review.

- The final published version features the final layout of the paper including the volume, issue and page numbers.

Link to publication

\section{General rights}

Copyright and moral rights for the publications made accessible in the public portal are retained by the authors and/or other copyright owners and it is a condition of accessing publications that users recognise and abide by the legal requirements associated with these rights.

- Users may download and print one copy of any publication from the public portal for the purpose of private study or research.

- You may not further distribute the material or use it for any profit-making activity or commercial gain

- You may freely distribute the URL identifying the publication in the public portal.

If the publication is distributed under the terms of Article 25fa of the Dutch Copyright Act, indicated by the "Taverne" license above, please follow below link for the End User Agreement:

www.tue.nl/taverne

Take down policy

If you believe that this document breaches copyright please contact us at:

openaccess@tue.nl

providing details and we will investigate your claim. 


\section{Effects of Fit and Bonding Characteristics of Femoral Stems on Adaptive Bone Remodeling}

\section{H. Weinans}

\author{
R. Huiskes \\ Section of Biomechanics, \\ Institute of Orthopedics, \\ University of Niimegen, \\ P.0. Box 9101 \\ 6500 HB Nijmegen, \\ The Netherlands \\ Mem. ASME
}

\author{
H. J. Grootenboer \\ Department of Biomedical Engineering, \\ Faculty of Mechanical Engineering, \\ University of Twente, \\ Twente, The Netherlands
}

\begin{abstract}
Bone atrophy caused by stress-shielding may cause serious complications for the long-term fixation of hip sterns. In particular, uncemented total hip arthroplasty is threatened by this problem, because the stems are usually larger and, as a consequence, stiffer than those of cemented implants. In the present study, the effects of fit and bonding characteristics of femoral hip stems were investigated, using the (nonlinear) finite element method in combination with adaptive bone remodeling theory to predict the bone density distribution in a bone or bone/implant configuration. Unknown parameters used in the theory, such as a reference equilibrium loading stimulus and a threshold (dead) zone of this stimulus, were established (triggered) by using the method to predict the density distributions in the natural femur and around fully coated uncemented implants. The computer simulation method can provide long term predictions of remodeling patterns around various implant configurations. Several cases were analyzed, whereby the coating conditions (fully, partly, or noncoated) and the fit characteristics (press fitted or overreamed) were varied. The computer predictions showed that partly coating can only significantly reduce bone atrophy relative to fully coated sterns, when the coating is applied at a small region at the utmost proximal part of the stem. For smooth press-fit stems the predicted amount of bone loss (35 percent in the proximal medial region) was less than for a one-third proximally coated or a fully coated stem (50 to 54 percent predicted bone loss in the proximal medial region). The results showed that overreaming the femoral canal in the press fit case can have important effects. Distal overreaming gave reduced proximal atrophy. Proximal overreaming (or undersizing) resulted in a distal jam of the stem, a proximal "stress-bypass," and dramatic proximal bone loss (up to 90 percent).
\end{abstract}

\section{Introduction}

Uncemented femoral hip prostheses have two main unfavorable qualities, which may cause serious complications. First of all, they usually do not fit very well (Noble et al., 1988; Schimmel and Huiskes, 1988), which may result in reduced initial stability and lack of bonding. Second, they are usually rather stiff, thereby reducing bone stresses, particularly in the proximal part of the femur. This phenomenon is generally referred to as "stress-shielding." It is assumed that this induces bone atrophy, which is indeed often observed postoperatively (Engh et al., 1987; Rosenberg, 1989). Whether this will create significant long-term clinical problems, such as bonding failure, loosening, or bone fracture, is uncertain as yet. It is certain, however, that when too much bone is lost, the fixation strength is jeopardized and prospects for a successful revision operation are diminished.

Several alternative designs, relative to implant stiffness, implant materials (composites) and coating size and locations have been introduced in the past, to minimize stress-shielding.

\footnotetext{
Contributed by the Bioengineering Division for publication in the JournaL of Biomechanical EngineERING. Manuscript received by the Bioengineering Division February 1, 1993; revised manuscript received November 16, 1993. Associate Technical Editor: S. Goldstein.
}

However, these efforts have not been very systematic and well documented. In order to optimize designs relative to stress shielding and bone loss, quantitative information is required about the relationship between design features and bone loss.

Turner et al. (1986) and Sumner et al. (1992) investigated the effects of several types of femoral stem coatings, using THA in dogs. They concluded that a partial proximal coating can reduce the amount of bone loss, relative to a fully coated implant. Proximally, however, the effects in terms of cortical bone loss around the partially coated stems were similar to those around fully coated ones. Engh et al. (1987) investigated the effects of proximally coated stems versus fully coated stems in a $2-5$ year clinical follow-up study, using radiographs. Fully coated and two-thirds proximally coated stems did show more bone resorption than the one-third proximally coated ones. Many commercially available, uncemented coated femoral stems now use the latter concept of a one-third, or at least partly, proximally coated area. Gruen et al. (1991) studied the bone response associated with partly porous-coated femoral stem components radiographically, after a follow-up period in the range of 5 to 6 years, with special attention to the initial fit of the stem. They found an increased intra-cortical porosity, 


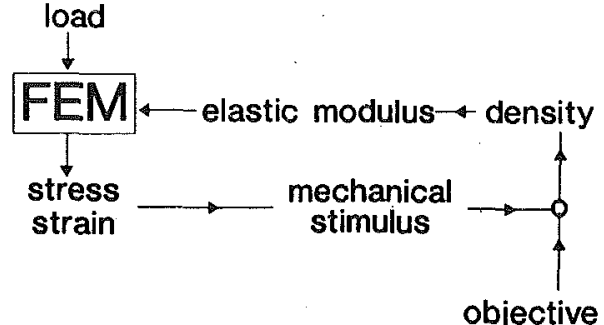

Fig. 1 Scheme of the bone remodeling simulation process incorporated in the finite element method

especially in the medial neck region, associated with proximally undersized femoral stems. Geesink et al. $(1988,1989)$ reported a follow-up study of proximally hydroxyl-apatite coated stems after a relatively short postoperative period (12 to 18 months), whereby apposition of dense bone against the coating of the prosthesis near the distal coating edge was found. There were no signs of cortical bone loss after 18 months.

Several attempts have been made to predict bone-morphology adaptations mathematically (Frost, 1964; Pauwels, 1965; Kummer, 1972; Cowin and Hegedus, 1976; Fyhrie and Carter, 1986; Huiskes et al., 1987, 1992; Weinans et al., 1992). It is assumed in these theories, that a mechanical variable is sensed by bone cells, and (combined with genetic, metabolic and hormonal factors) regulates the activation of osteoblasts and osteoclasts, whereby net bone formation or resorption can take place. The mechanical variable or signal assumed, in terms of stress or strain, however, often differs. Another important difference in these theories concerns the assumed equilibrium relationship between the signal and bone maintenance.

Cowin and Hegedus (1976) proposed a site-specific equilibrium relationship, with the strain tensor as the assumed remodeling signal. Site-specific implies that the relationship between net remodeling activity (in terms of bone density or geometry changes) and remodeling signal is location dependent. The remodeling activity depends on the difference between the actual strain and the strain under normal physiological conditions in a normal bone at the same location. Predictions of the normal morphology cannot be made with such a description, because the theory uses the strain state in the normal morphology as the reference equilibrium strain. Hence, the reference strains can only be calculated when both normal density distribution and normal loading conditions are known. This strategy was also followed by Cowin (1987), Hart et al. (1984), and Huiskes et al. (1987). Fyhrie and Carter (1986) assumed a nonsite-specific formulation, not dependent on the location in the bone. Their formulation implies that the morphology, in both normal and abnormal conditions, is a result of the external loading history exclusively (Carter et al., 1989).

Both formulations or rules can be used in conjunction with the finite element method, by which the internal loads in the bone, in terms of stresses or strains are determined (Carter et al., 1990; Hart et al., 1984; Huiskes et al., 1987, 1992; Weinans et al., 1989, 1992a,b). Weinans et al. (1993) and van Rietbergen et al. (1993) used such a finite-element integrated procedure to predict the bone morphology changes around a noncemented femoral stem in the dog and validated the simulation results with animal experiments (Turner et al., 1986; Sumner et al., 1992). The computer simulation results compared very favorably with those of the animal experiments, even to a considerable detail. Huiskes (1990) showed that the degree of stress shielding around a femoral stem is affected, first of all by the bonding conditions of the implant/bone interface and secondly by the stem stiffness (i.e., stem thickness and elastic modulus). The purpose of the present study is to evaluate the effects of fit and implant/bone bonding characteristics on the long-term morphology changes in the bone, due to stress-shielding. For this purpose, we exercise a computational model using a mathematical formulation with a non-site specific hypothesis of adaptive bone remodeling theory in combination with finite element models. The methods used in this study are the same as used earlier in Weinans et al. (1992b) to study the effects of femoral stem material properties on bone remodeling.

\section{Methods}

A schematic representation of the computer simulation procedure applied is shown in Fig. 1. The FEM supplies the stresses and strains in the bone structure. From these mechanical variables, a stimulus is determined, which controls the bone-remodeling rate. The morphology is represented by the apparent density of the bone only. The relation between the stimulus and the bone-density rate of change is described in a remodeling rule in which the objective of the remodeling process is incorporated. The actual bone density is then related to the modulus of elasticity of the bone, hence an updated input for the FEM model. The iterative procedure stops when the objective is reached or when the bone density has reached its maximum or minimal value (Weinans et al., 1990; Weinans et al., 1992a,b).

The objective used in the simulation procedure reflects the assumption that bone strives to equalize the strain energy per unit of bone mass, averaged over a particular loading history (Carter et al., 1989):

$$
\frac{1}{n} \sum_{i=1}^{n} \frac{U_{i}}{\rho}=\frac{U_{a}}{\rho}=k
$$

where $U_{i}(\mathrm{MPa})$ is the strain energy density (SED) for loading case $i$, as calculated in a continuum model of the bone material (hence the apparent SED), $U_{a}$ is the average SED over $n$ loading cases, $\rho\left(\mathrm{g} / \mathrm{cm}^{3}\right)$ is the apparent density and $k$ is a constant, called the "reference stimulus." Since $U_{i}$ is nonlinearly related to the external loads, $n$ separate finite element analyses must be executed to determine $U_{a}$. Equation (1) can be considered as a non-site specific formulation of the assumed equilibrium relationship for the adaptive bone remodeling process, since $k$ is equal through the entire bone. The quantity $U_{a} / \rho$ (Joules/ gram) represents the remodeling stimulus and is assumed to be sensed by bone cells, to determine whether net bone formation or resorption is to take place.

Hence, when $U_{a} / \rho-k \neq 0$ there is a driving force which regulates the amount of net bone formation or resorption. When this driving force is negative, bone resorption will occur. A positive driving force will induce bone formation. We assume that the driving force value (negative or positive) requires a minimum threshold in order to induce a bone reaction. This assumption was introduced by Frost (1964) as a 'minimum inhibitory signal' and adopted in adaptive remodeling theories (Beaupre et al., 1990a, 1990b; Cowin, 1987; Huiskes et al., 1987; Weinans et al., 1992b) as a "lazy zone" or a "dead zone." We assume a dead zone around the reference stimulus $k$, representing the expectation that bone will not remodel if it is close enough to the reference state $k$. Hence, in that case, the stimulus $U_{a} / \rho$ comes within the dead zone, between the values $k \pm s k$. It is proposed that bone resorption by osteoclastic activity occurs faster than bone formation by osteoblastic activity (Frost, 1986, Parfitt, 1983). Accordingly, we assumed that the rate of density change for resorption is larger than the rate of density change for apposition, for an equal value of the driving force $\left|U_{a} / \rho-k\right|$. An hypothetical curve for the rate of change in apparent density as a function of the stimulus $U_{a} / \rho$ is shown in Fig. 2. This relationship can be described by the following set of equations: 


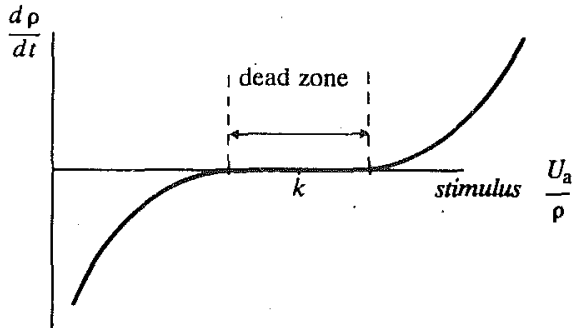

Fig. 2 Nonlinear relation between the rate of density change $(d \rho / d t)$ and the remodeling stimulus $\left(U_{a} / \rho\right)$

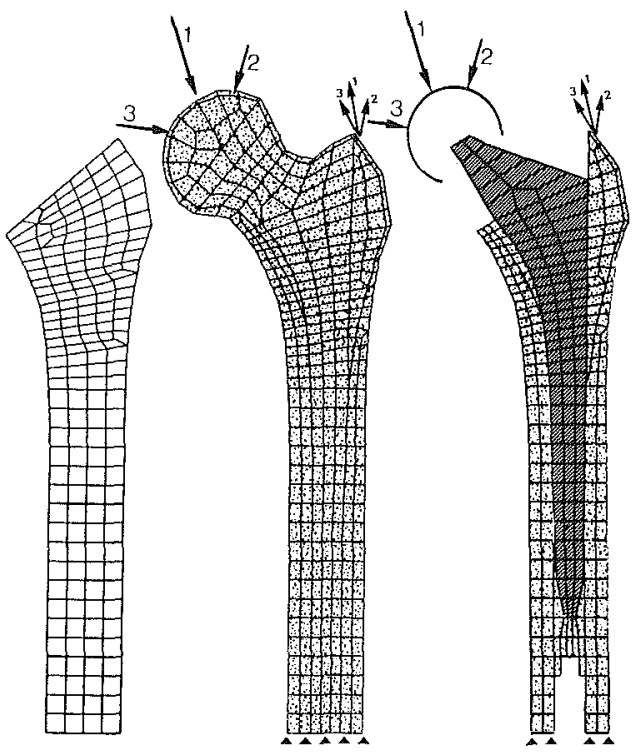

a) Normal femur with side plate

b) Uncemented stem

Fig. 3 The finite element model used in the simulations, similar to the one used in Weinans et al. (1992b). In the mesh of Fig. 3(b), the same side plate as shown in (a) is used. The magnitudes and directions of the hip joint $(j)$ and abductor forces (a) are for the different load cases, respectively: 1) $2317 \mathrm{~N}(j)$ and $702 \mathrm{~N}(a), 24$ degrees $(j)$ and 28 degrees (a) from vertical; 2) $1548 \mathrm{~N}(j)$ and $468 \mathrm{~N}(a), 56$ degrees $(j)$ and 35 degrees (a) from vertical; 3) $1158 \mathrm{~N}(j)$ and $351 \mathrm{~N}(a), 15$ degrees $(j)$ and 8 degrees (a) from vertical.

$$
\begin{gathered}
\frac{d \rho}{d t}=A\left\{\frac{U_{a}}{\rho}-k(1+s)\right\}^{2}, \text { if } U_{a} / \rho \geq k(1+s), \\
\frac{d \rho}{d t}=A\left\{\frac{U_{a}}{\rho}-k(1-s)\right\}^{3}, \text { if } U_{a} / \rho \leq k(1-s), \\
\frac{d \rho}{d t}=0, \text { if } U_{a} / \rho>k(1-s) \text { and } U_{a} / \rho<k(1+s), \\
\quad 0 \leq \rho \leq \rho_{\mathrm{cb}} .
\end{gathered}
$$

The constant $A$ regulates the rate of the process and is called the time constant. The present simulation model does not account for a realistic time scale, therefore $A$ is arbitrarily taken as 1.0 .

The boundary conditions for the predicted apparent densities (Eq. $(2 d)$ ) are taken as $0.01 \mathrm{~g} / \mathrm{cm}^{3} \leq \rho \leq 1.74 \mathrm{~g} / \mathrm{cm}^{3}$, where 1.74 $\mathrm{g} / \mathrm{cm}^{3}$ is the apparent density of cortical bone. A lower boundary of $0.01 \mathrm{~g} / \mathrm{cm}^{3}$ instead of $0.0 \mathrm{~g} / \mathrm{cm}^{3}$ is taken, since zero density will lead to zero stiffness in the FE-analyses, which will give numerical problems. The relation between the modulus of elasticity of the bone and its apparent density is taken from Carter and Hayes (1977):

$$
E=3790 \rho^{3}
$$

whereby the elastic modulus $E$ is expressed in $\mathrm{MPa}$ and the apparent density $\rho$ in $\mathrm{g} / \mathrm{cm}^{3}$. In the finite element model, the apparent density change per iteration is determined per element by forward Euler integration of Eq. (2) with a constant time step $\Delta t$, so:

$$
\begin{array}{r}
\Delta \rho=A\left\{\frac{U_{a}}{\rho}-k(1 \pm s)\right\}^{\alpha} \Delta t, \text { if } U_{a} / \rho \geq k(1+s) \\
\text { or } U_{a} / \rho \leq k(1-s),
\end{array}
$$

where $\alpha$ takes the value 2 (apposition) or 3 (resorption). The time step must be taken small enough, to guarantee convergence of the process (Weinans et al., 1989; Weinans et al., 1992a). The process is continued until an homeostatic equilibrium is reached (Weinans et al., 1992a), hence $d \rho / d t$ (Eq. (2)) has become zero, $\rho=\rho_{c b}$ or $\rho=0.01 \mathrm{~g} / \mathrm{cm}^{3}$.

First, the simulation model is used to determine the homeostatic density distribution in a normal femur (Carter et al., 1989; Weinans et al., 1989). A two dimensional finite element mesh of the proximal femur is constructed (Fig. 3(a)), using bilinear elements with four nodes. A side plate connects the periosteal medial and lateral sides of the model. So the front plate of the model represents a mid-frontal section of the femur and the side-plate is only used to account for the three dimensional elastic characteristics of the structure (Verdonschot and Huiskes, 1990). With this method accurate descriptions of the stress-strain distribution in the front plate can be accomplished (Huiskes, 1980; Huiskes, 1990; Verdonschot and Huiskes, 1990). Hence, only the front plate takes part in the remodeling process and the side plate maintains the same elastic modulus $(17,000 \mathrm{MPa})$ during the iterative process. The external loads were taken according to Carter et al. (1989), and consist of three different loading cases, as indicated in Fig. 3. Hence, the strain energy density $U_{a}$ in the remodeling process is determined from averaging over these three (separate) loading cases (Eq. (1)). The reference stimulus $k$ is based on previous analyses with the same model (Weinans et al., 1989; Weinans et al., 1992a,b), whereby $k$ was triggered on 0.0025 Joules/gram. The remodeling analysis starts with a uniform density distribution of the front plate. The iterative remodeling process is carried out with $s=0$ in Eq. (2), representing the assumption that in the prediction of the bone density distribution in the natural femur the reference objective is reached as good as possible. The density distribution found from this simulation represents the morphology of a normal femur under normal physiological loading conditions.

The solution for the normal bone is used as the initial density distribution for the simulation of the remodeling process of the bone surrounding a femoral component. Consequently, the finite element mesh of the normal femur (Fig. 3(a)) is modified to a mesh with a prosthesis (Fig. 3(b)). Again the same side-plate represents the out-of-plane cortical bone. Since the placement of the titanium prosthesis changes the stimulus values $U_{a} / \rho$ as determined in the model of the normal femur, the homeostatic equilibrium is disturbed and remodeling takes place according to Eq. (2). It is now assumed that the actual stimulus $\left(U_{a} / \rho\right)$ in the bone strives to approximate the same reference stimulus $k=0.0025 \mathrm{~J} / \mathrm{g}$. The dead zone is taken as \pm 35 percent of the reference stimulus, hence $s=0.35$, for all analyses with a prosthesis. This value was established by comparing the computer predictions of the fully coating stem with clinical data (Engh et al., 1987, 1992; Kiratli et al., 1991). The external loading cases are identical in magnitude, location and direction to the three loading cases considered for the normal femur (Figs. 3(a) and (b)).

Different replacement configurations were analyzed with this model, whereby contact conditions and fit between bone and implant were varied: a fully coated stem (Fig. 4(a)); a partly coated stem, with different sizes and locations of the coating area (Figs. $4(b, c$, and $d)$ ); a press-fit stem with no 


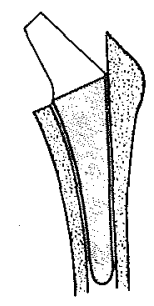

a) fully coated

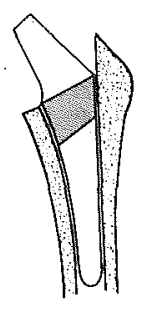

b) partly coasted

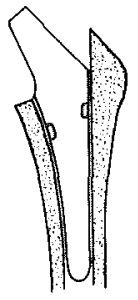

d) partly coatted

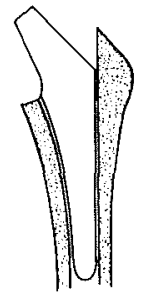

e) press fit

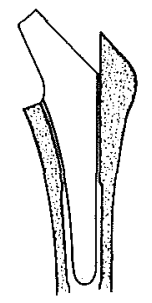

f) press fit

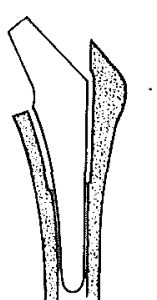

g) press fit

Fig. 4 Different configurations as subsequently analyzed with the FE. model. The coating is represented as a hatched area.

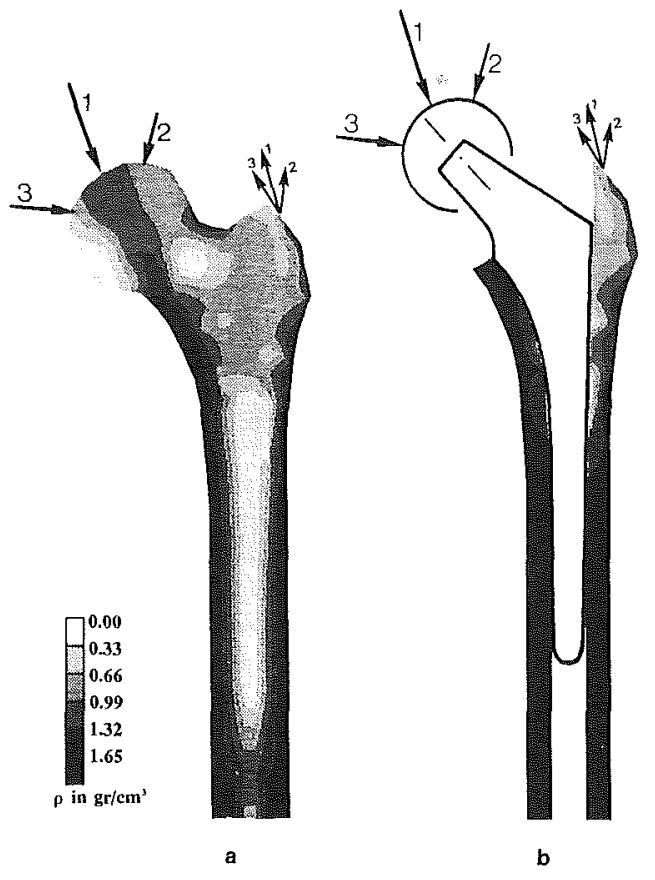

Fig. 5 Density distribution predicted by the computer simulation of a normal femur (a). The same density distribution as shown in (a) used in the FE-mesh of the femur with prosthesis, representing the configuration before remodeling has occurred (b).

coating and a smooth surface (Fig. 4(e)), assuming a frictionless interface; a press-fit stem with a $2 \mathrm{~mm}$ overreamed femoral canal distally (Fig. $4(f)$ ); a press-fit stem with a $2 \mathrm{~mm}$ overreamed femoral canal proximally (Fig. $4(\mathrm{~g})$ ). All stems were assumed to be made out of titanium (elastic modulus 110,000 $\mathrm{MPa}$ ). In all FEM models a completely bonded interface between stem and bone at the coated locations was assumed, representing complete ingrowth of bone at the coated areas. At the noncoated areas, smooth contact was assumed without any friction, hence at these locations only compressive stresses are transferred over the interface. In the finite element analyses, such a connection can be simulated using special contact elements, based on the imposition of additional constraints for the distance between two opposite nodes by Lagrange multipliers, representing the normal compressive force (MARC Analysis Research Corporation, Palo Alto, CA.). The nonlinear contact conditions were solved using a Newton-Raphson iteration method, whereby the iteration procedure stops when the maximal residual forces in the system were less then 5 percent of the maximal applied forces. After each iteration in the remodeling process this Newton-Raphson procedure is applied, whereby usually 3 to 5 iterations were needed. The overreamed areas (Figs. $4(f)$ and $(g)$ ) are modeled by a gap of 2 $\mathrm{mm}$ at the interface. Thus, if the relative displacement in the closing direction is larger than $2 \mathrm{~mm}$, contact takes place, and normal contact compressive forces are transferred. For the partly coated stem of Fig. 4(c) and the press fit stem with the precise fit (Fig. 4(e)), the relative motions between stem and bone were also determined, for loading case 2 (Fig. 3), under the condition that remodeling has not yet occurred.

\section{Results}

The density distribution as found in the remodeling simulation of the proximal femur without prosthesis is shown in Fig. 5(a). In a qualitative sense this result is similar to the distribution of a roentgenogram of a coronal midsection of the proximal femur (Brown and Ferguson, 1980). All important aspects of a real proximal femur can be recognized: the medial and lateral cortices, the intramedullary canal, the metaphyseal cortical shells, Ward's triangle and the typical densification patterns of the cancellous structure in the femur head and greater trochanter. Figure $5(b)$ shows the same bone, but with a prosthesis placed in the intramedullary canal, according to the mesh of Fig. 3(b). This configuration (Fig. 5(b)) was used as the initial one for simulations of the different replacement configurations studied, shown in Fig. 4.

The density distributions after bone-remodeling as predicted by the computer simulations for the different cases indicated in Fig. 4, are shown in the Figs. 6(a) through 6(g). The percentages bone loss were determined in four areas (Gruen zones, Gruen et al., 1979), which are also indicated in the figures. It should be noted that only the front plate takes part in the remodeling process, hence, the percentages indicated in Fig. 6 only refer to the front plate. The model predicted a relatively large amount of bone resorption in the proximal femur around the completely coated (titanium) implant (Fig. 6(a)). In the proximal areas 54 percent and 38 percent bone loss was found, for the medial and lateral sides, respectively. The upper part of the calcar was almost completely lost and even around the middle part of the stem some resorption was found (4 percent medially and 14 percent laterally). Using a partial coating of the proximal stem, reduced bone loss was found (Figure $6 b$ ). At the medial side the bone loss was 50 percent, which was only 4 percent reduction relative to the completely coated stem (from 54 to 50 percent) and again the upper part of the calcar had completely disappeared. At the lateral side 22 percent bone loss was found proximally and 5 percent in the mid-stem region. Relative to the fully coated stem, this was a significant reduction (from 38 to 22 percent lateral/proximally and from 14 percent to 5 percent in the lateral mid-stem region).

When the size of the partial coating was reduced to a small area at the same location as the distal rim of the partial coating of Fig. $6(b)$, the remodeling patterns hardly changed (compare Figs. $6(b)$ and $6(c)$ ). A small reduction of proximal bone loss was found only (from 50 to 48 percent medially and from 22 percent to 17 percent laterally). When such a small coating area was located at the utmost proximal part of the stem, a drastic reduction in bone loss did take place (Fig. $6(d)$ ). The 


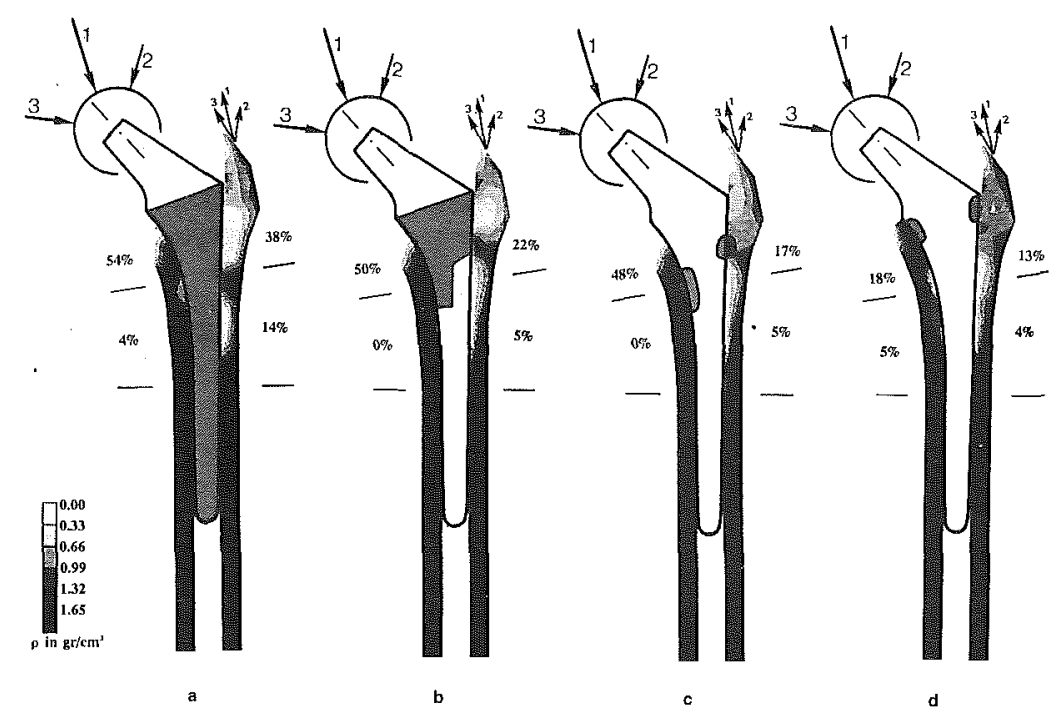

Fig. 6(a-d)

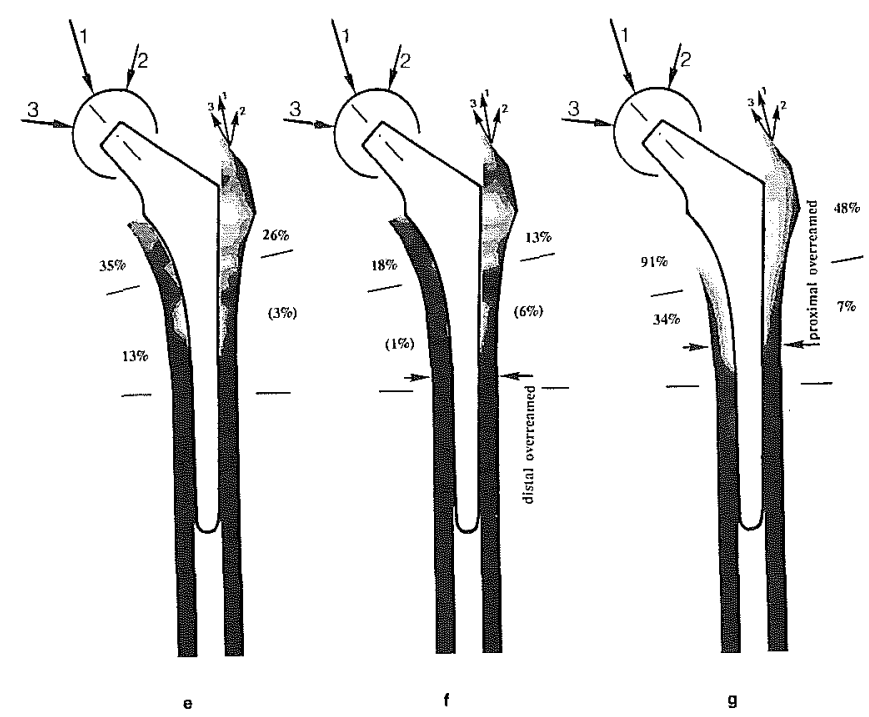

Fig. $6(e-g)$

Fig. 6 The density distribution as predicted by the computer simulation for the subsequent models. The amounts of bone loss (in mass) are indicaled in each figure in four different areas (Gruen zone's Gruen et al., 1979). Bone mass increase is indicated within brackets.

model predicted a small region of cortical bone which grew directly to the coating at the proximal medial side. Only some calcar resorption was found directly under the resection level. In comparison to the previous partially coated alternative, the proximal bone loss had decreased from 48 to 18 percent medially and from 17 to 13 percent laterally. At the medial side in the mid stem region, the percentage bone loss had increased somewhat, in comparison to the previous partial coatings (from 0 to 5 percent).

A smooth stem without coating (press-fit) demonstrated a completely different result after remodeling (Fig. 6(e)). The density in the proximal medial area decreased with 35 percent. Unlike all coated stems, there was still bone under the resection level in the calcar. Proximal/laterally 26 percent bone loss was found in this model. In the mid-stem area, bone resorption was predicted medially ( 13 percent), but at the lateral side an increase of 3 percent in bone density was found. A distally overreamed femoral canal enhanced this effect and led to mild proximal bone resorption only (Fig. 6(f)), similar to the partially coating alternative of Fig. $6(d)$. In the mid-stem area, this model produced a bone-density increase of 1 percent medially and 6 percent laterally. Overreaming the femur shaft proximally led to a dramatically opposite effect, as shown in Fig. 6(g). In the proximal bone, severe bone loss was found, particularly in the calcar region (91 percent bone loss proximal/ medially and 48 percent loss proximal/laterally), probably related to a stress bypass in this area (Huiskes et al., 1989). Also in the mid-stem region a considerable amount of bone loss was predicted, again predominantly on the medial side ( 34 percent medially and 7 percent laterally). Table 1 summarizes the percentages bone loss $(-)$ or gain $(+)$ in the four zones for all subsequent analyses.

When the density patterns in the different models were analyzed more closely, two aspects were observed. First, at the 
Table 1 Percentages bone mass change at four different locations in the subsequent remodeling simulations

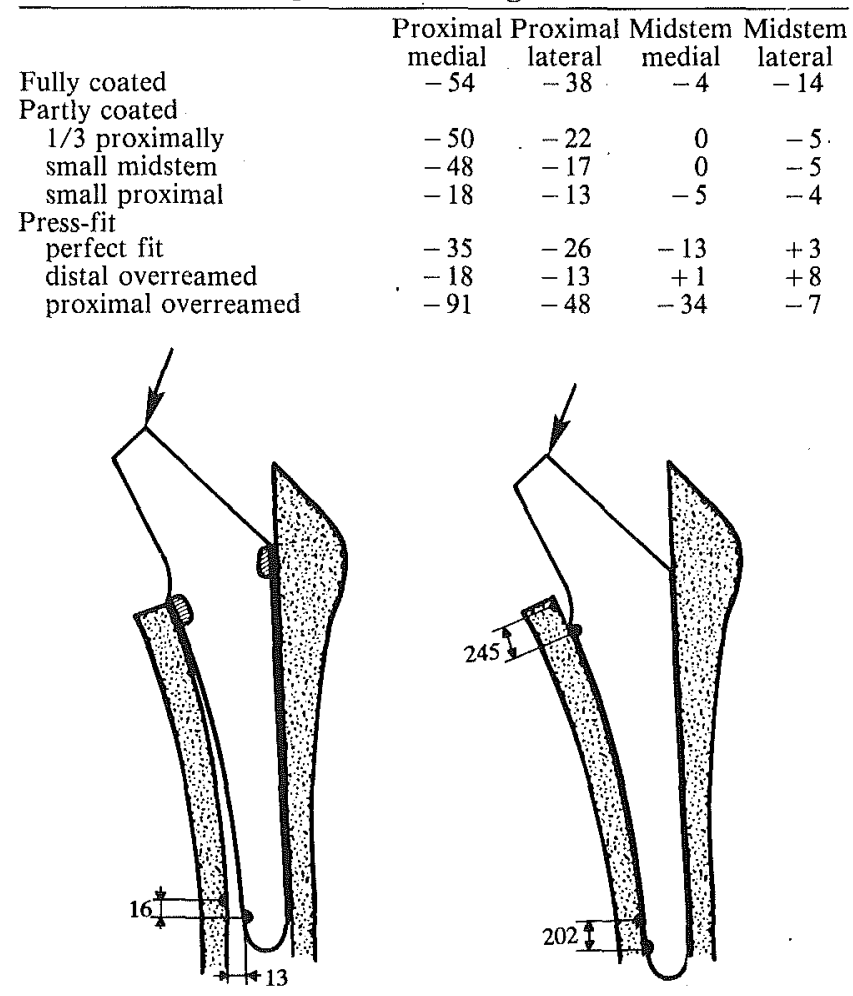

Fig. 7 Relative (micro) motions as found in the initial configuration of a partly coated stem and a smooth press fit stem

distal boundaries of the partial coating, bone densifications were found, which suggest high stress transfer at these points (Figs. 6(b), 6(c), and 6(d)). Second, in all models the density patterns showed relatively large gaps (similar to local osteolysis) close to the interface.

For the models of the Figs. $6(d)$ and $6(e)$, the relative motions were determined at the bone/prosthesis interface, for loading case 2 (Fig. 3) in the initial state, before remodeling had occurred. The results are shown in Fig. 7. As expected, the relative (micro) motions were considerably larger for the press-fit design than for the bonded one. The first underwent almost uniform longitudinal relative displacements (subsidence) in the range of about 200 to 245 microns. No motions in the transverse direction were found. It is likely that this was caused by the taper of the stem which caused relatively high circumferential compression (Huiskes, 1990). A partial coating prevented gross subsidence of the stem, and only marginal axial motion was found, increasing from zero at the top, where the implant was bonded, to 16 microns distally. The coating seemed to act as a pivot point, which caused some transverse displacements distally of 13 microns.

\section{Discussion}

This work shows that adaptive bone-remodeling computer simulation can be used as a powerful tool to evaluate the effects of implant design parameters. The need for these simulations becomes more important when geometry, coating conditions and stiffness of the stem interfer in a complex manner. In fact Kuiper and Huiskes (1992) and Kuiper (1993) showed that for bonded stems the initial stress shielding can also give a reasonable estimate of eventual adaptive bone resorption. With multifarious effects, investigated in the current parametric study, such as different (nonlinear) bonding conditions and overreaming, a full remodeling simulation analyses is.required to estimate the long-term density patterns of the remodeled bone.
The models used in this study do have their limitations. They are two-dimensional, whereby the front-plate represents the mid-frontal plane only. The anterior and posterior parts of the femur are represented by the side plate, but do not take part in the remodeling process. Hence, the bone loss can never extend along the circumference, as it might in reality. Although stress patterns are accurate for mid-frontal plane loading (Verdonschot and Huiskes, 1990), the present models cannot account for the effects of torsional loads, caused by forces out of the mid-frontal plane. In addition, the 2-D side plate models can not generate hoop stresses but instead normal stresses in the transverse direction of side plate and front plate will be generated. The overall behavior in terms of scalar quantities like von Mises stress or elastic energy is similar in the front plate of a 2-D model and a coronal section of a full 3-D model (Verdonschot and Huiskes, 1990). Without the side plate it is impossible in a remodeling analysis to obtain realistic density distributions in the metaphyseal and diaphyseal parts. This can be illustrated from studies of Carter et al. (1989), Beaupré et al. (1990a, 1990b), and Orr et al. (1990). They were interested predominantly in the density patterns of the femoral head and greater trochanter, and used a two-dimensional model of the proximal femur, similar to the one in this study, but without a side plate. Hence, the density distributions found in the femoral head and trochanter areas were similar to the ones shown in Fig. 5(a), but no normal density distribution (for example, the intramedullary canal) was found in the more distal areas, where the side plate is more important for the validity of the model. Further limitations of the present models are that there is no surface remodeling of cortical bone, the bone material properties are isotropic in both cortical and cancellous regions, and finally the time course is normalized to $A=1.0$ (Eq. (2)), so there is no account of the real time required to reach the adapted state.

An important aspect of the present remodeling model is that the density can become inhomogeneous (Weinans et al., 1992; Harrigan and Hamilton, 1992) as a consequence of the applied remodeling equations. The end configuration usually consist of cortical elements of which the stimulus value has surpassed the reference stimulus (Weinans et al., 1992a). For the density distribution of the normal femur as shown in an interpolated pattern in Fig. 5(a), this is certainly true for the areas where trabecular bone is predicted (femoral head and trochanter). Weinans et al. (1992) assumed that the inhomogeneities are related to the local trabecular pattern in case the model would be very refined. For the presentation of apparent densities, such as in this study, interpolated smoothed results are believed to be appropriate.

It must be emphasized that two parameter values in the remodeling Eqs. (2) were tuned. The first is the value of $k$, which was triggered to the model of the normal femur. The value of the reference stimulus $k$ (Eq. (1)) determines the amount of bone mass in the whole structure. A smaller $k$ leads to more bone mass. In the normal femur analysis no dead zone was assumed in order to reach the reference objective $k$ as closely as possible. The value of $k$ was scaled to a value of 0.0025 Joules per gram such that a realistic end configuration was predicted by the model. The remodeling analyses of the normal femur model was performed only to supply the initial density distribution for the models with prostheses. This initial density distribution is in fact represented by the value of the triggered reference stimulus $k$. A rough estimate of $0.0025 \mathrm{~J} /$ $\mathrm{g}$ in terms of strain gives 660 microstrain, in case of a uniaxial load on a piece of cortical bone $(E=20,000, \rho=1.74)$. Hence, this is in the ballpark of physiological loading conditions. The other parameter which is triggered is $s$ (Eq. (2)), representing the width of the dead zone. The concept of a dead zone was suggested frequently in the literature and was given different names by different authors (Frost, 1964; Beaupre et al., 1990; Carter, 1984; Cowin, 1987; Huiskes et al., 1987). In this study 
we found that unrealistic bone loss, throughout the entire cortex, was predicted by the model with the fully coated stem when no dead zone was taken into account (Huiskes et al., $1989 \mathrm{~b}$ ). The same conclusion was reached in the simulation of animal experiments (Weinans et al., 1993 and Van Rietbergen et al., 1993) where a dead zone of \pm 35 percent of the reference stimulus $k$ also produced satisfactory results. The same value of \pm 35 percent taken in the present analyses was based on the comparison between the simulation with the fully coated stem and clinical data (Engh et al., 1992; Kiratli et al., 1991). It must be appreciated that the model concerned is an empirical one and other parameter values may provide a similar result. In this study the extent of the dead zone was equal for all models analyzed here. A different value would not change the relative effects of the different bonding conditions studied, which was the primary goal of this study. Hence, a relative interpretation of the results, by comparing them to each other gives the most valuable information.

It is difficult to find accurately documented clinical studies in the literature, suitable to validate the present results quantitatively. Several clinical X-ray studies reported bone loss following THA in a qualitative sense (Engh et al., 1987; Engh and Bobyn, 1988; Gruen et al., 1991; Rosenberg, 1989; Thomas et al., 1986). Accurate percentages of bone loss can not be obtained from these studies, since the traditional radiographic techniques used require up to 30 percent change in bone density before it can be detected. Dual energy X-ray absorptiometry can give accurate quantitative data concerning the amount of bone remodeling around implants in specific locations in the bone. However, these techniques are not widely used as yet. Recent studies using this technique for uncemented (Kiratli et al., 1991; Engh et al., 1992) and cemented THA (Steinberg et al., 1991) emphasized that even after more than three years following a THA, continued bone resorption takes place. Kiratli et al. (1991) reported about 20 to 30 percent bone loss around uncemented porous coated stems in some specific prox$\mathrm{imal} / \mathrm{medial}$ bone regions, after $2-5$ years post-operatively. Engh et al. (1992) reported a bone mineral content decrease in the range of 24 to 83 percent, with a mean of 45 percent, in the proximal area around extensively ( 80 percent) porous coated uncemented hip stems. In the mid stem region the bone loss reported by Engh and associates was still extensive up to 67 percent for some cases (mean 32 percent). These results fit reasonably well with the range of bone mass reductions found in the present numerical study. It is important to realize that the results of the models represent end-configurations, indicating a new homeostatic equilibrium. In most clinical studies it is unclear to which extent the remodeling process has proceeded, whether it continues or has come to an end.

The results from this study showed that a fully or partly coated stem may induce drastic proximal-bone atrophy (Figs. $6(a)$ and $6(b))$. A reduction of the coating of the utmost proximal rim only can prevent this, although still some proximal bone loss was predicted in that case (Fig. 6(c)). It is obvious, however, that the interface stresses for the partially coated prosthesis from Fig. 7(a) may be very high at the coated area, dependent on the exact size and location of this coating. This was shown also by the remodeling patterns found around the partly coated stems, where a bridge of cortical bone to the distal medial rim of the coating was predicted (Figs. $6(b),(c)$, and $(d)$ ). These bone bridges correspond with the locations where high interface stresses were found (Huiskes, 1990). In Fig. $6(b)$, this "bridging"' was also found at the lateral side at both edges of the coating. This density pattern was confirmed clinically by Gruen et al. (1991) and Geesink et al. $(1988,1989)$. This reflects an important principle design contradiction, that proximally concentrated stress transfer reduces bone loss, but increases the prospects for interface failure.

A smooth press-fit design can reduce bone resorption considerably, in particular, when it fits only proximally. This implies that a relatively short press-fitted stem, an undersized distal part, or distal overreaming are favorable for bone maintenance. It should be noted, however, that such an unbonded press-fit stem provokes relatively large (micro) motions between bone and implant (Schneider et al., 1989; Walker et al., 1987), as demonstrated in Fig. 7. When the implant looses all longitudinal support, which can be provided by friction or ingrowth, it subsides over its entire length. This will certainly result in high compressive interface stresses, depending on the geometry of the stem, in particular the shape of the taper (Huiskes, 1990). It is probable that relative motions between implant and bone generate endosteal resorption and soft-tissue interposition (Eftekar et al., 1985; Perren, 1983). In addition, this concept of stem fixation generates high hoop stresses which increase the chances of bone fracture. It should be noticed that the present isotropic model is too simplified to represent this phenomenon in a realistic three dimensional way.

Finally, the worst case of bone resorption was predicted for the distally fitted stem, where the proximal bone was assumed to be overreamed, or the proximal stem undersized (Fig. 6(g)). In that case a stress bypass is produced, similar to what was suggested as the cause for findings in some animal experiments with press-fitted prostheses (Huiskes et al., 1989a; van Rietbergen et al., 1993). This finding emphasizes the importance of fit. Adequacy of fit in individual cases depends, of course, on surgical technique. However, in view of the variety in proximal femoral geometry (Noble et al., 1988), one may question whether the design concept of a stem to be fitted reasonably precisely over its full length is realistic at all. It is likely that clinical cases in which dramatic proximal bone resorption around press-fitted stems is seen (e.g., Draenert, 1988) suffered from precisely this mechanism, an ill-fitting proximal part or, in other words, a distal jam. If, conversely, the stem fits well proximally, but not distally, only mild bone resorption will result. In that case, one may wonder about the actual role of the distal stem part.

\section{References}

Beaupré, G. S., Orr, T. E., and Carter, D. R., 1990, "An Approach for Time-Dependent Bone Modeling and Remodeling-Application: A Preliminary Remodeling Simulation," J. Orthop. Res., Vol. 8, p. 662.

Beaupré, G. S., Orr, T. E., and Carter, D. R., 1990, "An Approach for Time-Dependent Bone Modeling and Remodeling-Theoretical Development," J. Orthop. Res., Vol. 8, p. 651.

Brown, T. D., and Ferguson, A. B., 1980, "Mechanical Property Distributions in the Cancellous Bone of the Human Proximal Femur," Acta. Orthop. Scand., Vol. 51, p. 429 .

Carter, D. R., and Hayes, W. C., 1977, "The Behavior of Bone as a TwoPhase Porous Structure," J. Bone Joint Surg., Vol. 59A, p. 954.

Carter, D. R., 1984, "Mechanical Loading Histories and Cortical Bone Remodeling," Calcif Tissue Int., Vol. 36, p. S19.

Carter, D. R., Orr, T. E., and Fyhrie, D. P., 1989, "Relationships Between Loading History and Femoral Cancellous Bone Architecture," J. Biomech,, Vol. 22 , p. 231.

Cowin, S. C., and Hegedus, D. H., 1976, "Bone Remodeling I: Theory of Adaptive Elasticity," J. Elasticity, Vol. 6, p. 313.

Cowin, S. C., 1987, "Bone Remodeling of Diaphyseal Surfaces by Torsional Loads: Theoretical Predictions," J. Biomech., Vol. 20, p. 1111.

Draenert, K., 1988, "Forchung und Fortbildung in der Chirurgie des Bewegungsapparates 2," Munich, Art and Science.

Engh, C. A., Bobyn, J. D., and Glassman, A. H., 1987, "Porous Coated Hip Replacement: The Factors Governing Bone Ingrowth, Stress Shielding, and Clinical Results," J. Bone Jt. Surg., Vol. 69B, p. 45.

Engh, C. A., and Bobyn, J. D., 1988, "The Influence of Stem Size and Extent of Porous Coating on Femoral Bone Resorption after Primary Cementless Hip Arthroplasty," Clin. Orthop., Vol. 231, p. 7.

Engh, C. A., McGovern, T. F., Bobyn, J. D., and Harris, W. H., 1992, "A Quantitative Evaluation of Periprosthetic Bone-Remodeling After Cementless Total Hip Arthroplasty," J. Bone Jt. Surg., Vol. 74A, pp. 1009-1020.

Eftekar, N. S., Doty, S. B., Johnston, A. D., and Parisien, M. V., 1985, "Prosthetic Synovitus," p. 169, R. H. Fitzgerald, ed., The Hip, Proc. 13th Meeting of the Hip Soc., St. Louis, CV Mosby Co.

Frost, H. M., 1964, The Laws of Bone Structure, Charles C. Thomas Publisher, Springfield, IL.

Frost, H. M., 1986, Intermediary Organization of the Skeleton, Vol. I, Boca Raton, FL, CRC Press. 
Frost, H. M., 1987, "Vital Biomechanics. Proposed General Concepts for Skeletal Adaptations to Mechanical Usage," Calcif. Tissue Int., Vol. 42, p. 145. Fybrie, D. P., and Carter, D. R., 1986, "A Unifying Principle Relating Stress to Trabecular Bone Morphology," J. Orthop. Res., Vol. 4, p. 304.

Geesink, R. G. T., 1988, "Hydroxyl-Apatite Coated Hip Implants," Ph.D. thesis, University of Limburg, Maastricht, The Netherlands.

Geesink, R. G. T., 1989, "Experimental and Clinical Experience with $\mathrm{Hy}$ droxyapatite-Coated Hip Implants," Orthopedics, Vol. 12, p. 1255.

Gruen, T. A., McNeice, G. M., and Amstutz, H. C., 1979, "Modes of Failure of Cemented Stem-Type Femoral Components, A Radiographic Analysis of Loosening," Clin. Orthop., Vol. 141, p. 17.

Gruen, 'T. A., Hedley, A. K., Borden, L. S., and Hungerford, D. S., 1991, "Adaptive Bone Remodeling Associated With Cementless Porous Coated Femoral Total Hip Replacement Components. Five Year Minimum Follow-up Radiographic Analysis," Presented at the 58th Annual Meeting of the American Academy of Orthopaedic Surgeons, Scientific Exhibit, Anaheim, CA, Mar.

Harrigan, T. P., and Hamilton, J. J., 1992, "An Analytical and Numerical Study of the Stability of Bone Remodeling Theories: Dependence on Microstructural Stimulus," J. Biomech., Vol. 25, pp. 447-488.

Hart, R. T., Davy, D. T., and Heiple, K. G., 1984, "Mathematical Modelin and Numerical Solutions for Functionally Dependent Bone," Calc. Tissue Int. Huiskes, R., 1980, Vol. 36, p. S11. "Some Fundamental Aspects of HumanJoint Replacement," Acta Orthop. Scand. 185 (Suppl.).

Huiskes, R., Weinans, H., Grootenboer, H. J., Dalstra, M., Fudala, B., and Slooff, T. J., 1987, "Adaptive Bone-Remodeling Theory Applied to ProstheticDesign Analysis," J. Biomech., Vol. 20, p. 1135.

Huiskes, R., Weinans, H., Sumner, D. R., Fudala, B., Turner, T. M., Grootenboer, H. J., and Galante, J. O., 1989a, "Stress-shielding, Stress-Bypassing and Bone Resorption Around 'Press-Fit' and Bone Ingrowth THA," Trans. 35th Annual Meeting of the Orthop. Res. Soc., p. 529, Las Vegas, Feb.

Huiskes, R., Weinans, H., and Dalstra, M., 1989b, "Adaptive Bone-Remodeling and Biomechanical Design Considerations for Noncemented Total Hip Arthroplasty," Orthopedics, Vol. 12, p. 1255.

Huiskes, R., 1990, "The Differing Stress Patterns of Press-Fit, Ingrown and Cemented Femoral Stems," Clin. Orthop., Vol. 261, p. 27.

Huiskes, R., Weinans, H., van Rietbesyen, B., 1992, "The Relationship between Stress Shielding and Bone Resorption around Total Hip Stems and the Effects of Flexible Material," Clin. Orthop., Vol. 274, p. 124.

Kiratli, B. J., Heiner, J. P., McKinley, N., Wilson, M. A., McBeath, A. A., 1991, "Bone Mineral Density of the Proximal Femur after Uncemented Total Hip Arthroplasty," Trans. 37th Annual Meeting of the Orthop. Res. Soc., p. 545, Anaheim, Ca, Mar.

Kuiper, J. H., and Huiskes, R., 1992, "The Predictive Value of Stress Shielding for Quantification of Adaptive Bone Resorption Around Hip Replacements," Trans. ESB Meeting, p. 159.

Kuiper, J. H., 1993, "Numerical Optimization of Artificial Hip Joint Designs," Ph.D. thesis, University of Nijmegen, The Netherlands.

Kummer, B. K. F., 1972, "Biomechanics of Bone: Mechanical Properties, Functional Structure, Functional Adaptation," p. 237, Y. C. Fung, N. Perrone, M. Anliker, ed.," Biomechanics: Its Foundation and Objective, Prentice Hall Englewood Cliffs, NJ.

Noble, P. C., Alexander, J. W., and Granberry, M. L., 1988, "The Myth of 'Press-Fit' in the Proximal Femur," Scientific Exhibit of the 55th Annual Meeting of the AAOS, Atlanta, GA, Feb.

Noble, P. C., Alexander, J. W., Lindahl, L. J, Yew, D. T., Granberry, W. M., and Tullos, H. S., 1988, "The Anatomic Basis of Femoral Componen Design," Clin. Orthop., Vol. 235, p. 148

Orr, T. E., Beaupré, G. S., Carter, D. R., and Shurman, D. J., 1990, "Com- puter Predictions of Bone Remodeling around Porous-Coated Implants," $J$. Arthropl., Vol. 5, p. 191

Parfitt, A. M., 1983, "The Physiologic and Clinical Significance of Bone Histomorphometric Data," p. 143. Recker, R. R., ed., Bone Histomorphometry: Techniques and Interpretation, Boca Raton, FL, CRC Press.

Pauwels, F., 1980, Gesammelte Abhandlungen zur Funktionellen Anatomie des Bewegungsapparates, Springer, 1965. Translated as Biomechanics of the Locomotor Apparatus, Spring-Verlag, Berlin.

Perren, S. M., 1983, "The Induction of Bone Resorption by Prosthetic Loosening," p. 156. Morcher, E., ed., The Cementless Fixation of Hip Endoprostheses, Springer, Berlin.

Rietbergen, van B.; Huiskes, R., Weinans, H., Sumner, D. R., Turner, T. M., Galante, J. O., 1993, "The Mechanism of Bone Remodeling and Resorption Around Press-Fitted THA Stems,"'J. Biomech., Vol. 26, p. 369.

Rosenberg, A., 1989, "Cementless Total Hip Arthroplasty: Femoral Remodeling and Clinical Experience," Orthopaedics, Vol. 12, p. 1223.

Sarmiento, A., Gruen, T. A., 1985, "Radiographic Analysis of Low-Modulus Titanium-Alloy Femoral Total Hip Component," J. Bone Jt. Surg., Vol. 67A, p. 48 .

Schimmel, J. W., and Huiskes, R., 1988, "The Primary Fit of the Lord Cementless Total Hip," Acta Orthop. Scand, Vol. 59, p. 638.

Schneider, E., Eulenberger, J., Steiner, W., Wyder, D., Friedman, R. J., and Perren, S. M., 1989, "Experimental Method for the In Vitro Testing of the Initial Stability of Cementless Hip Prostheses," J. Biomech., Vol. 22, p. 735.

Steinberg, G. G., Kearns McCarthy, C., and Baran, D. T., 1991, "Quantification of Bone Loss of the Femur after Total Hip Arthroplasty," Trans. 37th Annual Meeting of the Orthop. Res. Soc., p. 221, Anaheim, CA, Mar.

Sumner, D. R., Turner, R. M., Urban, R. M., and Galante, J. O., 1992,

"Remodeling and Ingrowth at Two Years in a Canine Cementless Total Hip Arthroplasty Model," J. Bone Jt. Surg., Vol. 74-A, pp. 239-250.

Thomas, B. J., Salvati, E. A., and Small, R. D., 1986, "The CAD Hip Arthroplasty," J. Bone Jt. Surg., Vol. 68A, p. 640.

Turner, T. M., Sumner, D. R., Urban, R. M., Rivero, M. D., and Galante, J, O., 1986, "A Comparative Study of Porous Coatings in a Weight-Bearing Total Hip-Arthroplasty Model," J. Bone Jt. Surg., Vol. 68A, p. 1396.

Verdonschot, N., and Huiskes, R., 1990, "FEM Analyses of Hip Prostheses: Validity of the 2-D Side-Plate Model and the Effects of Torsion," Trans. 7th Meeting of the Europ. Soc. Biomech., p. A20, Arhus, Denmark, July.

Walker, P. S., Schneeweis, D., Murphy, S., and Nelson, P., 1987, "Strains and Micromotions of Press-fit Femoral Stem Prostheses," J. Biomech. Vol. 20, p. 693.

Weinans, H., Huiskes, R., and Grootenboer, H. J., 1989, "Convergence and Uniqueness of Adaptive Bone Remodeling," Trans. 35th Annual Meeting of the Orthop. Res. Soc., p. 310, Las Vegas, Feb.

Weinans, H., Huiskes, R., and Grootenboer, H. J., 1990, "A Hypothesis Concerning Minimal Bone Density Threshold Levels as Final Stages of Bone Remodeling," Trans. 36th Annual Meeting of the Orthop. Res. Soc., p. 79, New Orleans, Feb.

Weinans, H., Huiskes, R, and Grootenboer, H. J., 1992a, "The Behavior of Adaptive Bone-Remodeling Simulations Models," J. Biomech., Vol. 25, pp. 1425-1441.

Weinans, H., Huiskes, R, and Grootenboer, H. J, 1992b, "Effects of Material Properties of Femoral Hip Components on Bone Remodeling," J. Orthop. Res., Vol. 10, pp. 845-853.

Weinans, H., Huiskes, R, Rietbergen, B, yan, Sumner, D. R., Turner, T. M., and Galante, J. O., 1993, "Adaptive Bone-Remodeling Around Bonded Noncemented THA: A Comparison Between Animal Experiments and Computer Simulation," J. Orthop. Res., Vol. 11, pp. 500-513. 